\title{
SÍNDROMES DA ASSISTÊNCIA DE ENFERMAGEM
}

NURSING CARE SYNDROME.

\section{Maria Aparecida de Luca Nascimento ${ }^{1}$ Elvira de Felice Souza ${ }^{2}$}

RESUMO: O presente estudo tem como objetivo principal descrever as "síndromes da assistência de enfermagem" que são observadas durante o exercício profissional do enfermeiro, além de propor a criação de uma nova linha de pesquisa voltada para a descrição das mesmas. A autora traça um paralelismo entre as iatrogenias e as referidas síndromes, enfatizando que a proposta de descrevê-las tem como finalidade o aspecto preventivo. No desenrolar do estudo, após algumas considerações históricas concernentes ao desenvolvimento da prática profissional e de como a mesma é praticada atualmente, surge a conceituação das "síndromes da assistência de enfermagem", que é uma exortação ao profissional de enfermagem para que visualize a sua prática de forma mais abrangente pautando-a na observação acurada e no questionamento de procedimentos que são realizados de forma mecânica, repetitiva e institucionalizada.

UNITERMOS: Síndrome - Assistência - Procedimentos.

\begin{abstract}
This paper has as a principal goal to describe the 'nursing care syndrome' that appears while nursing care is provided. From the conceptualization of 'nursing care syndrome' besides other, aspects, it points out the difference between the latter and the iatrogenicities as well as between the clinical syndromes and the nursing care ones.
\end{abstract}

KEYWORDS: Syndrome - Nursing care - Procedures.

\section{INTRODUÇÃO}

Durante os meus vinte e três anos de prática profissional, a maior parte deles dedicados ao cuidar de crianças, quer seja como assistente ou docente, (onde também a carga horária tem a sua maior parte voltada para o ensino clínico) vários procedimentos concernentes à enfermagem chamaram a minha atenção.

\footnotetext{
${ }^{1}$ Professor Adjunto do Departamento de Enfermagem Materno-Infantil da Escola de Enfermagem Alfredo Pinto da Universidade do Rio de Janeiro (UNI-RIO) - Doutora em Enfermagem.

${ }^{2}$ Professor Emérito da Universidade Federal do Rio de Janeiro (UFRJ) - Doutora em Enfermagem
} 
Percebia que os profissionais de enfermagem desempenhavam varias atividades de forma mecânica e repetitiva, sem questionar outras maneiras que poderiam ser adotadas para a realização das mesmas técnicas.

Muitas vezes estes procedimentos padronizados desencadeavam nas crianças reações emocionais passiveis de observação, desconforto a partir de contrações musculares determinadas por posições anômalas do corpo ou segmento assim como outros sinais subjetivos que se instalavam gradativamente. No entanto estas reações passavam despercebidas aos profissionais, uma vez que não eram referenciadas pela criança nem pela sua mãe.

Com relação ao procedimento das mães ou acompanhantes, vale ressaltar que muitas vezes elas, além de não perceberem qualquer acometimento, também agiam como fator agravante da situação ao perceberem e omitirem qualquer intercorrência com a criança que pudesse determinar a intervenção da enfermagem com a finalidade de modificar o "status quo".

Desse modo o equilibrio das ações se estabelecia a partir de dois agentes; por um lado, o profissional que desempenhava as suas funções sem questionamentos e convencido de que aquela era a melhor maneira de assim fazê-lo (uma vez que normalmente estas práticas eram institucionalizadas), e por outro lado, a mãe que se submetia a toda e qualquer situação que àquela altura era considerada benéfica ao tratamento.

Estes procedimentos realizados pela equipe de enfermagem, normalmente eram revestidos de boa vontade ao fazê-lo, e a sua repetitividade assegurava ao profissional de que aquele era o melhor caminho a seguir.

No entanto, a partir da minha inquietação ao perceber estas atividades de enfermagem que determinavam a instalação de vários sinais na criança, tentei encontrar respaldos bibliográficos que pudessem corroborar a sua perpetuação.

Pude constatar que o repasse do "como fazer" determinadas técnicas durante a formação e a repetição delas durante o exercício profissional do enfermeiro eram os responsáveis por tal situação. Era como se a cada dia do exercício profissional houvesse um reforço da aprendizagem da técnica adquirida durante a formação, sendo por isto muitas vezes visualizada como um procedimento burilado e aprimorado.

Este trabalho tem como preocupação fundamental conceituar as "síndromes da assistência de enfermagem", que advêm dos cuidados prestados durante a assistência de enfermagem de um modo geral e em particular durante a assistência de enfermagem pediátrica. 


\section{Objetivos}

geral

- Descrever, através de conceituação, as "síndromes da assistência de enfermagem, visando a prevenção, diminuição e/ou eliminação dos seus riscos.

\section{específicos}

- Descrever, através da conceituação das "síndromes da assistência de enfermagem", o paralelismo existente entre estas e as iatrogenias.

- Propor uma linha de pesquisa voltada para a descrição de "síndromes da assistência de enfermagem", com a finalidade de expandir esse conhecimento.

\section{RELEVÂNCIA DO ESTUDO}

O presente estudo, ao descrever as sindromes da assistência de enfermagem, encontra a sua maior relevância ao possibilitar uma maior preocupação com fatos diretamente referidos aos cuidados de enfermagem., dos quais dependem sua instalação e/ou agravamento.

Essa relevância é também estendida à área da educação, ao possibilitar que sejam repensadas várias técnicas durante o ensino de graduação do enfermeiro e técnico dos demais profissionais da área de enfermagem - que são repassadas da mesma maneira, sem questionamentos e/ou alternativas para melhor fazê-lo.

Sendo o enfermeiro, através do seu perfil de educador, o responsável pelos repasses técnicos em suas funções, quer sejam elas docentes (no âmbito dos ensinos técnico ou universitário ) ou assistenciais, será através da discussão de medidas alternativas entre esses profissionais que as síndromes da assistência de enfermagem poderão ser evitadas e/ou minimizadas.

Outro fato relevante é que a partir do presente trabalho será possivel formar uma linha de pesquisa, voltada para a caracterização de "síndromes da assistência de enfermagem", o que favorecerá um planejamento mais rápido e acurado da assistência, com ênfase nas ações preventivas.

\section{AS TÉCNICAS DE ENFERMAGEM}

\section{ASPECTOS HISTÓRICOS E CONCEITUAIS}

A assistência de enfermagem deve ser prestada ao cliente de um modo geral, respeitando as suas particularidades, e deve exigir, do profissional que a implementa, conhecimentos específicos, treino, destreza e habilidades pessoais 
(Souza, 1978,p.23). De um modo particular, a assistência de enfermagem pediátrica, por causa de seus aspectos altamente diferenciados, nuances e implicações, exige que o profissional seja provido de atenções adicionais que são fundamentais ao atendimento das especificidades que são inerentes à própria vulnerabilidade infantil.

As técnicas de enfermagem são procedimentos ministrados durante o ensino de graduação, que têm como principais objetivos, segundo Koch et al.(1978, p.13), proporcionar sequrança e conforto àquele que está sendo submetido ao cuidado, assim como economia de tempo e esforço a quem cuida, e de material à instituição onde o processo de cuidar se realiza.

O procedimento técnico encontra respaldo na própria herança histórica da Enfermagem, quando, ao surgir nos Estados Unidos, no início do século $X X$, organizou e sistematizou uma forma de prestar cuidados ao cliente através dos procedimentos técnicos, estruturando o seu saber através deles, que já àquela época eram considerados como arte (Almeida, 1986, p. 29).

A consideração de que a arte, configurada através da estética, intuição e criatividade, se expressava nas ações de enfermagem foi primeiramente observada por Florence Nightingale no século XIX .Segundo ela, esses valores emergiam durante o ato de cuidar (Waldow et al., 1995, p. 53).

No entanto, foi ao associar a ciência à arte, ainda segundo a autora supra referenciada, que Florence Nightingale permitiu não só que houvesse o rompimento das muitas superstições que permeavam as ações de enfermagem, através dos conhecimentos advindos das suas pesquisas, como também a integração entre o pensar e o sentir conferindo à enfermagem uma característica humanística.

O ato de cuidar, portanto, assume uma dimensão técnica, organizada e sistematizada porém permeada de subjetividade, deixando de ser somente uma ação prática, fria e racional.

Desse modo, ao deixar emergir situações onde estariam expressas qualidades intrínsecas ao seu próprio ser, o profissional de enfermagem, durante a execução das técnicas, estaria creando, (neologismo de onde se originou a palavra criar) que segundo Rhoden (1981, p. 5); é a própria manifestação da essência em forma de existência.

Desta forma, o cuidar em enfermagem pode ser visualizado como um conjunto de ações técnicas, subsidiadas de conhecimento científico e desenvolvidas com arte.

ARTE, por definição, entre outras, do Dicionário da Academia Brasileira de Letras, (Nascentes,1988, p. 66), é o ato de utilizar um "conjunto de preceitos 
para a perfeita execução de qualquer coisa", "execução prática de uma idéia ", ou ainda, "perícia em usar os meios para atingir um resultado".

Segundo essa definição, a visualização da Enfermagem como arte, difundida através das suas técnicas, não anula a sua associação à ciência, pois, ao lançar mão de um conjunto de preceitos científicos para o seu desenvolvimento, estaria conferindo ao cuidar uma característica ampla e inconfundivel. Esta característica é determinada pelo profissional de enfermagem, que, ao fazê-lo, utiliza a sua habilidade manual, revestida do seu potencial intelectual. (Almeida, 1986, p. 26).

Apesar do ato de cuidar constituir um atributo para todos os profissionais da área da saúde, na enfermagem ele é genuíno e peculiar, constituindo a razão existencial dessa profissão (Waldow et al., p. 8 ). Porém ,observa-se que, a partir de alguns procedimentos técnicos na enfermagem, surgem efeitos adversos, não diagnosticados, por serem na sua maior parte subjetivos e silenciosos.

Esta lacuna existente tanto no ensino quanto no desenvolvimento da prática profissional, sob o ponto de vista técnico, permitindo que efeitos adversos durante e a partir do cuidado de enfermagem se instalem, apesar de contemporâneo, encontra respaldo na preocupação de Nightingale (1989, p.1415) quando, ao se referir à prática de enfermagem, citou:

A arte de enfermagem, atualmente como é praticada (1860), parece ter sido criada para desfazer o que Deus determinou que a doença fosse, isto é; um processo restaurador.

O fato de alguns procedimentos técnicos terem sido repassados ao longo do tempo durante o ensino de enfermagem e desenvolvidos pelo profissional após a sua formação, do modo como é feito atualmente, não invalida o fato dos mesmos serem repensados em prol da prestação do cuidado de enfermagem de uma forma holística, o que aliás é um dos propósitos deste estudo.

Esta preocupação é consoante à nova visão no atendimento de saúde, e que está sendo objeto de preocupação da bioética. Segundo Garrafa (1995, p.19), entre a dialética questão da "beneficência" e de "não - maleficência" nascem as principais mudanças com vistas à melhoria da qualidade dos cuidados prestados à população. Desse modo, os procedimentos que foram formalizados a partir da sua prática devem começar a ser questionados.

Ainda segundo o autor acima referenciado, (1995, p. 15), a bioética poderia ser definida como sendo:

"a procura de um comportamento responsável de parte daquelas pessoas que devem decidir tipos de tratamento." 
A preocupação com os efeitos adversos oriundos de procedimentos técnicos, assim como o repensar desta prática a partir da formação profissional do enfermeiro, está fundamentada no pensamento bioético de Garrafa (1995, p. 15), quando cita:

(...). Tendo descartado en nome da objetividade qualquer fornia de subjetividade(...), a racionalidade científica não pode - sozinha - estabelecer os fundamentos da bioética...Além da honestidade, do rigor científico ou da procura da verdade - pre'-requisitos de unia boa formação científica, a reflexão bioética pressupõe algumas questões humanas que não estão incluidas nos currículos universitários " (...)

A multiplicidade de aspectos que são envolvidos no ato de cuidar em enfermagem, uma vez que a mesma tem por finalidade devolver a saúde ou até mesmo evitar a morte de um ser humano, encontra respaldo na citação de Carrafa (1995, p.15)

"No sentido amiplo que se pretende dar à bioética, seus verdadeiros fundamentos somente poden ser encontrados através de uma ação multidisciplinar que inclua alén das ciência médicas e biológicas, também a filosofia , o direito(...)“.

Desse modo, a necessidade da descrição das síndromes da assistência de enfermagem surgiu a partir da prática profissional de enfermagem, porém associada à observação de múltiplos aspectos de ordem fisiológica, psicológica, comportamental, filosófica e jurídica.

\section{CONCEITUAÇÃO DE "SÍNDROMES DA ASSISTÊNCIA DE ENFERMAGEM"}

Tendo em vista que um dos pontos relevantes do presente estudo é propor uma linha de pesquisa voltada para a descrição de síndromes da assistência de enfermagem, torna-se necessária a sua conceituação .

Por oportuno vale ressaltar que, neste estudo, à palavra LESÃO será atribuído o sentido conferido à mesma pelo Dicionário da Academia Brasileira de Letras (Nascentes, 1988,p.376 ) - "Ato ou efeito de lesar; dano material que fere o corpo ou patrimônio; alteração patológica de um orgão ou função de um indivíduo".

Ainda segundo a obra supra referenciada ( 1988,p.278), FERIR é definido como sendo o "ato de causar dano", "causar sensação", e ainda como sendo "mudança estrutural e funcional dos tecidos e órgãos que causam doenças ou são determinados por elas". 


\section{Deste modo, as síndromes da assistência de enfermagem são definidas como se segue:}

“Conjunto de lesões, danos, ou ainda, sensações que podem ser observados durante a assistência de enfermagem, quer seja a partir dessa própria assistência, quer seja pela condição conjuntural do momento em que a mesma é prestada.

As síndromes da assistência de enfermagem, portanto, advêm, segundo a definição etimológica previamente estipulada, de um dano corporal que fere o corpo, ou ainda como resultado de uma sensação provocada pela mudança estrutural e funcional dos tecidos, causada ao cliente durante a assistência de enfermagem.

As síndromes da assistência de enfermagem originam-se de procedimentos imperiosos, que ao serem realizados pela equipe de saúde determinam outros procedimentos, realizados exclusivamente pela equipe de enfermagem, e que seriam os responsáveis pela sua instalação.

Desta forma, os procedimentos imperiosos captariam as atenções ao serem dispensados, ao passo que os procedimentos coadjuvantes ficariam em segundo plano, sendo os responsáveis pela instalação das síndromes da assistência de enfermagem, que podem ser classificadas em vários estágios a partir de seus efeitos cumulativos de forma mediata, imediata e tardia.

Vale ressaltar que a diferenciação entre síndromes da assistência de enfermagem e iatrogenias causadas durante a assistência de enfermagem (que são malefícios causados ao cliente por imperícia, negligência ou imprudência no atendimento) diz respeito à identificação de sintomas subjetivos, através dos sinais impressos no corpo, que caracterizam a síndrome, $e$ a visualização de sinais objetivos como resultado da iatrogenia.

Enquanto as iatrogenias podem ocorrer a partir de um fato isolado, as síndromes da assistência de enfermagem se caracterizam por estarem incorporadas ao cotidiano dessa assistência, sendo praticada de forma repetitiva e institucionalizada.

A proposta de caracterização de síndromes da assistência de enfermagem, tem o objetivo de evitá-las, o que a diferencia de síndrome clínica, por ser esta ,segundo Blakiston (1970, p.75), um conjunto de sinais e sintomas que possibilitam um diagnóstico a partir da sua caracterização, a título de tratamento, podendo ser reversível ou não" 


\section{CONCLUSÃO}

Atualmente, observa-se que, sob pena de serem rotulados como "funcionalistas", os trabalhos científicos da enfermagem vêm se distanciando do objeto de estudo que tenha como foco o cuidado direto ao cliente, priorizando outras áreas de igual importância dentro da profissão, mas que, por não pertencerem unicamente à enfermagem, não a distinguem com a exclusividade que a assistência o faz.

O FAZER em enfermagem tornou-se objeto de poucos estudos em relação a outros de igual valor, que por serem difundidos têm merecido lugar de destaque na nossa profissão. No entanto, é o FAZER que determina através da sua prática a evolução e/ou adaptação de antigos conceitos no ato de assistir (Nascimento, 1995,p.2).

Deste modo, a perspectiva de desenvolvimento de novos estudos a partir da descrição das "síndromes da assistência de enfermagem" observadas durante a prática assistencial, propiciará à enfermagem condições de não só readaptar e emancipar as suas técnicas como também respaldá-las científicamente a partir de uma visão crítica e questionadora.

Este estudo, longe de apresentar uma conclusão, uma vez que este é um caminho que se inicia, pretende exortar os profissionais de enfermagem a observarem , descreverem e divulgarem ,a partir da sua prática profissional, "as sindromes da assistência de enfermagem", conferindo ao ato de cuidar uma visão científica, ampla e abrangente, dignificando desta forma ainda mais a nossa profissão.

\section{BIBLIOGRAFIA}

1. ALMEIDA, Maria Cecilia Puntel; ROCHA, Juan. O saber da Enfermagem. São Paulo: Cortez, 1986. 127 p.

2. BARNETT, Kathryn. A theoretical construct of the concept of touch as they related to nursing. Nursing Research, v.21, n.2, p.102-109, march- april 1972.

3. BLAKISTON. Dicionário Médico. São Paulo: Andrei, 1970. 1001 p. 
4. GARRAFA, Volnei . Dimensão da Ëtica em Saúde Pública. São Paulo, EDUSP, 1995. $71 \mathrm{p}$.

5. $\mathrm{KOCH}$, Rosi M. et al. Técnicas Básicas de Enfermagem. 2 ed. Curitiba: Litero - Técnica, 1978. 119 p.

6. NASCENTES, Antenor Dicionário da Língua Portuguesa._Rio de Janeiro:Bloch, 1988,667 p.

7. NASCIMENTO,Maria Aparecida de Luca. A Arte Ciência e Tecnologia na Enfermagem - Registro de Patentes (Relato de Experiência). Rio de Janeiro:Cultura Médica ,1996. (No prelo)

8. NIGHTINGALE, Florence. Notas de Enfermagem - o que é e o que não é. São Paulo: Cortez, 1989. 174 p.

9. RHODEN, Humberto . Pascal. São Paulo: Alvorada, 1981.

10. SANTOS , Mário Ferreira dos. Convite à estética . São Paulo: Logos, 1964.

11. SCHMITZ, Edilza Maria et al. A enfermagem em Pediatria e Puericultura. Rio de Janeiro - São Paulo : Atheneu , 1989,477 p.

12. SILVA, Maria Júlia Paes da. Percebendo os sentimentos de maneira não verbal. Rev. Paul. Enf., São Paulo, p. 1, n.3, p. 128 - 32 , set. / dez., 1991.

13. SOUZA, Elvira De Felice. Novo Manual de Enfermagem. 6. ed. Rio de Janeiro: Cultura Médica ,1978. 481 p.

14. VISCOTT, David. A Linguagem dos sentimentos. São Paulo : Summus, 1982. $135 \mathrm{p}$.

15. WALDOW, Vera Regina et alii - Maneiras de cuidar, maneiras de ensinar - a enfermagem entre a escola e a prática profissional. Porto Alegre: Artes Médicas, 1995.203 p. 
16. WEIL, Pierre; TOMPAKOW, Roland. O Corpo fala - a linguagem silenciosa da comunicação não verbal. 20. ed. RJ : Vozes. 1988, 279 p.

17. WHALEY, Lucille F.; WONG, Donna. Essentials of Pediatric Nursing._Toronto: Mosby, 1989. $909 \mathrm{p}$.

18. ZLOTOWICZ, Michel. Os medos infantis. Rio de Janeiro: Zahar, 1976. 186 p. 